\title{
Design Thinking e seus códigos visuais na gestẫo de design para inovação: inovação incremental pelo modelo geida
}

Design Thinking and its visuals codes in the design management for the innovation: incremental innovation by sidme model

Ana Paula Perfetto Demarchi ${ }^{1}$

Cleuza Bittencourt Ribas Fornasier ${ }^{2}$ Rosane Fonseca de Freitas Martins ${ }^{3}$ 


\section{Resumo}

O presente artigo visa propor reflexões acerca da relação entre a inovação baseada no design, que traz avanços de significado e lida com conhecimentos de linguagens e significações, códigos visuais e a Gestão Estratégica de Design. Para tanto, apresenta um compêndio teórico sobre a inovação baseada em design; habilidades e técnicas do designer, que são facilitadoras para o desenvolvimento de produtos e serviços inovadores (e delimita quando, como, e porque serão utilizadas no modelo GEiDa - Gestão Estratégica integradora de Design atualizado). A Natureza da pesquisa classifica-se como exploratória, com delineamento ex-post-facto, utilizando como estratégia a etnografia por meio de entrevista e observação não participante. Após a aplicação do modelo evidencia-se que se trata de uma estrutura conceitual que permite a aplicação do Design Thinking como ponto de partida; é um meio que possibilita atingir a inovação incremental baseada em design; e aponta a inovação como ponto de chegada e uma porta de entrada definitiva para o design como ferramenta fundamental de estratégia competitiva. Demonstra, ainda, como o modelo GEiDa pode levar a empresa a adotar a inovação incremental por meio da inovação baseada em design.

Palavras-Chave: gestão do design; inovação baseada em design; design Thinking; códigos visuais

\section{Abstract}

Currently in Brazil, business people are in search of tools and processes related to innovation, attentive to issues of markets internationalization such as: new behaviors of users; proactive actions of competition; quality standards; among other factors, and begin to see in design a strategy for innovation. Not necessarily the process of new product development, technological innovation, but innovation driven by design which brings meaning advances dealing with knowledge of languages and meanings. This article aims to demonstrate how the model Strategic Integrator Design Management enhanced (SiDMe) can lead companies to adopt incremental innovation through innovation driven by design. To make both a theoretical compendium on innovation driven by design and; the designer's skills and techniques which are facilitators for the development of innovative products and services, and to define when, how, and why will be used within the model SiDMe. The nature of research was exploratory, with delineation by the ex-post-facto, using ethnography as a strategy, through the non-participant observation and interview. After the application of the model it is evident that this is a conceptual framework that allows the application of Design Thinking and through this achieving incremental innovation driven by design

Keywords: Design Management; Innovation driven by design; design Thinking; Visual codes

ISSN: $1808-3129$

\footnotetext{
PhD pela Universidad Politécnica de Valencia, Departamento de Ingeniería Gráfica (2014), Doutora em Engenharia e Gestão Conhecimento pela Universidade Federal de Santa Catarina - Brasil perfeto@sercomtel.com.br

${ }^{2}$ PhD pela Universidade Politécnica de Valencia, no Departamento de Engenharia Gráfica (2014- bolsista CNPq), Doutora em Engenharia e Gestão do Conhecimento pela Universidade Federal de Santa Catarina - Brasil cleuzafornasier@gmail.br

${ }^{3}$ Doutora em Engenharia de Produção/Gestão Integrada do Design (2004) pela Universidade Federal de Santa Catarina (UFSC). - Brasil rosaneffm@gmail.com
} 


\section{Introdução}

Atualmente, o design é reconhecido como uma estratégia de inovação, porque por excelência é uma atividade de inovação. Os consumidores, cada vez mais autores do próprio consumo, e atentos ao valor (estético, simbólico e emocional dos produtos), que é transmitido pela linguagem de design (combinação de sinais -formas, cores, materiais- que dão sentido a um produto) que tem mobilizado as empresas a empregar esforços para definir estratégias adequadas (ou a adequação) da linguagem de design dos seus produtos, já que o próprio design é tido como estratégia de diferenciação, pois é responsável pela forma atribuída à marca, produtos e processos, que por sua vez equivale a uma proposição a ser interpretada. Articular signos para atingir efeitos comunicativos pragmáticos está na essência do Design (Romanini, 2008).

Entre essas estratégias (incluindo escolher por sinais) e processos inovadores, uma abordagem tem ganho espaço: o design thinking. $\mathrm{O}$ design thinking, segundo Brown (2009) beneficia-se da capacidade humana de ser intuitivo, reconhecer padrões, desenvolver ideias que tenham um significado, além de funcional, emocional e de se expressar em mídias além de palavras ou símbolos (capacidades esquecidas por práticas convencionais de resolução de problemas). É uma proposta humana pela própria natureza e não apenas centrada no ser humano.

Obviamente, uma empresa não é gerenciada com base apenas em sentimentos como intuição e inspiração, mas pode ser perigoso a gerencia somente no racional e no analítico. A abordagem integrada que reside no centro do processo de design sugere um terceiro caminho (BROWN, 2009).

Hoje, para lidar com esse consumidor-autor na velocidade que ele exige, com seu design thinking (neste caso, trata-se da sua capacidade de escolher, interpretar, combinar livremente serviços, produtos e estéticas) (MORACE, 2009), e cujo sentido se relaciona com novos valores e experimentos, manifestos por comportamentos e parâmetros sugeridos e sustentados pelas novas tecnologias. As organizações, na ânsia por inovação, podem entender que o processo de inovação radical é arriscado e pressupõem custos ou investimentos muito altos. Neste contexto, optam por buscar a inovação incremental.

A inovação incremental baseada em tecnologia muitas vezes é difícil de conseguir, assim, as organizações começam a buscar a inovação baseada em design, ou seja, aquela centrada em significação.

Designers têm ampliado sua ação, saindo da posição tradicional de desenvolver processos e produtos, na qual tratam de questões como estilo e ergonomia, para uma maior contribuição na geração de novos conceitos e gerenciamento da imagem (no sentido amplo) em torno desses conceitos. Para isso, utilizada habilidades de compreensão das necessidades dos consumidores (usuários/autores/expectadores).

O processo de gestão estratégica de design baseado no design thinking, aqui apresentado, representa um modelo conceitual que auxiliará o designer neste novo papel, potencializando as suas habilidades, tornando-se uma ferramenta para inovação baseada em design (DEMARCHI, FORNASIER e MARTINS, 2013). 


\section{Inovação}

Terra et al. afirma que "inovar significa ter uma ideia nova ou, aplicar a ideia de outros de uma forma original e com eficácia" (TERRA, 2007). Mas não é só: é uma nova ideia aliada à implementação, ou a exploração com sucesso de novas ideias. $O$ termo inovação é empregado em pelo menos três diferentes contextos:

- sinônimo de invenção: refere-se a um processo criativo em que dois ou mais conceitos são combinados de uma forma nova para produzir uma configuração não conhecida;

- uma mudança: algo, processo e ou procedimento novo para a organização; e

- na visão popular algo prático ou artefato material: algo inventado ou visto como novo independente de sua adoção (XAVIER, 2014).

A lei da inovação a define como "a concepção de novo produto ou processo de fabricação, bem como a agregação de novas funcionalidades ou características ao produto ou processo que implique melhorias incrementais e efetivo ganho de qualidade ou produtividade, resultando maior competitividade no mercado". ( http:// www.planalto.gov.br/ccivil_03/_Ato2004-2006/2004/Lei/L10.973.htm, acesso maio 2015).

Em 1995, Higgins (XAVIER, 2014) especificou três níveis de inovação: incremental, semirradical e radical.

- Incremental é a inovação predominante na maioria das empresas. São pequenas e práticas mudanças que podem ser aplicadas em modelos de negócios, produtos ou serviços, pois “(...) são uma maneira de extrair o máximo valor possível de produtos e serviços existentes sem a necessidade de fazer mudanças significativas ou grandes investimentos".(DAVILA, EPSTEIN, SHELTON, 2007). Um exemplo pode ser o uso de tecnologias e formas existentes.

- Semirradical: em comparação com as inovações incrementais, esta consegue alavancar mudanças importantes envolvendo alterações no modelo de negócio ou na tecnologia da empresa.

- Radical: consiste em mudanças no modelo de negócio e na tecnologia da empresa e normalmente provocam alterações significativas no mercado. É possível que a inovação radical seja seguida de outros níveis de inovações, mas que ocasionem melhoria no produto. É primordial a avaliação minuciosa do investimento nesse tipo de inovação, pois "inovações radicais são, pela própria natureza, investimentos de pouca probabilidade de retorno"(DAVILA, EPSTEIN, SHELTON, 2007). Pelo menos em curto prazo, pois altera o comportamento social, rompendo com o já existente.

A inovação tecnológica é toda a novidade implantada pelo setor produtivo, por meio de pesquisas ou investimentos, que aumenta a eficiência do processo produtivo ou que implica num produto novo, ou aprimorado. É, portanto, inovação de produto ou de processo ( MANUAL DE OSLO, 2015).

Outros tipos de inovações, podem se relacionar a novos mercados, novos modelos de negócio, novos processos e métodos organizacionais, novas fontes de suprimentos e é diferente de processos de inovação com melhoria contínua e processos relacionados a esse tema. 
Para que seja inovação é necessário que haja um impacto significativo na estrutura de custos, de preços, na participação de mercado, na receita da empresa, etc.. Normalmente, as melhorias contínuas não são capazes de criar vantagens competitivas em médio e longo prazo, mas de manter a competitividade dos produtos em termos de custo.

A figura 1, a seguir, ilustra uma inovação, pois uma alteração no design gráfico da embalagem, realizada pelo estúdio Folia dos Reis, implicou em uma mudança significativa na estrutura de custos, passando de 4 para 1 cor de impressão.

Já a embalagem da figura 2, de Ana Couto, apesar de ser bem mais "inovadora" do ponto de vista popular, não é uma inovação, pois não gerou impacto no processo ou no produto Rosa chá, embora seja diferente na forma. Entretanto, em longo prazo pode vir a ser, após análise e mensuração do retorno sobre o investimento.

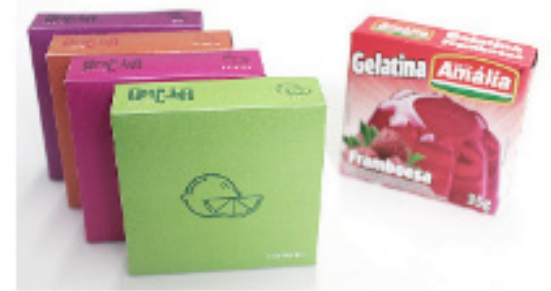

Figura 1: Alteração na embalagem gelatina Santa Amália - inovação incremental Fonte: http://www.foliadosreis.com/

A partir da 3ạ edição, do Manual de Oslo, 2005, editado pela OCDE ( MANUAL DE OSLO, 2015), responsável pelas definições mundiais adotadas sobre inovação, traz uma importante modificação: expandiu o conceito de inovação, incluindo o setor de serviços e retirando a palavra "tecnológica" da definição, ou seja, é possível se fazer inovação em produtos, em processos, em serviços, em marketing e em sistemas organizacionais.



Apresentamos, também, outra classificação que diferencia inovação fechada e inovação aberta (CHESBROUGH, 2012):

- A inovação fechada é uma abordagem que é fundamentalmente focada para dentro, e bem adequada aos paradigmas do início do século XX. Neste paradigma "as ideias são acompanhadas e filtradas durante os processos de pesquisa, e aquelas que sobrevivem a esse escrutínio são transferidas para o desenvolvimento e, então, colocadas no mercado". (CHESBROUGH, 2012).

- A inovação aberta é o paradigma que supõe "que as empresas podem e devem usar ideias externas da mesma forma que usam ideias internas e caminhos internos 
e externos para o mercado" ((TERRA, 2007), adapta-se aos paradigmas do sec. XXI. A figura 3 abaixo ilustra esta diferença.

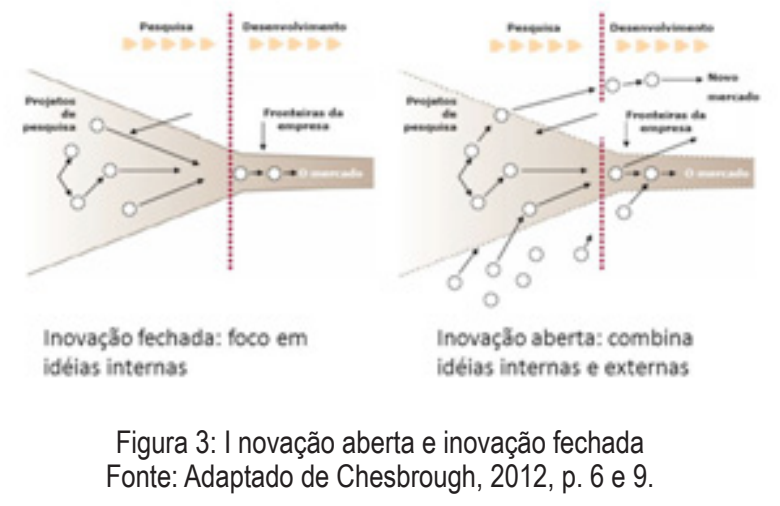

No sec. XXI as ideias não podem permanecer em estoque na prateleira, pois acabarão vazando para um ambiente maior. Precisam deste ambi-ente para se cocriarem, ser trazidas de volta para a organização e ser transformadas em novos produtos e serviços. Observa-se que os conhe-cimentos não estão centralizados nas instalações de pesquisa, mas são agrupamentos de variados conhecimentos distribuídos por todo cenário. Passa-se de um modelo de inovação fechada, representada por empresas que tinham os centros de desenvolvimento de pesquisa e criação de tecnologia, com verbas gigantescas, mas com produtos que nem sempre estavam alinhados com o mercado e atores extra muros/steackholders, para o modelo de inovação aberta.

Avaliou-se que todo o investimento pesado (e muitas tecnologias e produtos desperdiçados) em P\&D relacionado ao faturamento das empresas não garantia crescimentos e lucros sustentáveis, garantia uma pequena parcela de produtos que realmente tiveram sucesso. "Parte das soluções descartadas, [...] ignoradas e não valorizadas internamente, por total descuido na transferência para outros interessados, ressurgiam como soluções brilhantes e inovadoras em outras aplicações e produtos de outras empresas"( DAUSCHA, 2012).

Então, um processo de amadurecimento ocorre até se chegar no atual modelo de inovação aberta. Parceiros internos de atendimento, vendas e produção são ouvidos, fornecedores e clientes também, fazendo surgir a Inovação em Rede, logo passavam a envolver outros agentes, como Universidades e Institutos de Pesquisa e até concorrentes ( DAUSCHA, 2012), no desenvolvimento, por exemplo, de novas tecnologias para serem usadas de forma diferente na comercialização.

Com a experiência do desperdício de tecnologias e produtos gerados a partir do processo fechado de inovação, as empresas passam a gerenciar subprodutos do processo inovativo anterior, licenciando-os ou vendendo-os para interessados externos ou incentivando equipes e pessoas a fundarem novas empresas (chamado de spin-out). Para acelerar a incorporação de novas tecnologias e produtos no seu portfólio, no modelo da Inovação Aberta, as empresas preveem a compra ou licenciamento de tecnologias, assim como a aquisição de empresas de base tecnológica (chamadas de spin-in), ou a participação acionária em empresas alinhadas com a sua 
rota tecnológica.

Portanto, as empresas passam a praticar novas oportunidades de inovação. $O$ sec. XXI é o século da inovação aberta, que neste artigo demonstraremos um modelo que enfatiza a inovação baseada no design, para gerar inovação incremental baseada no Design Thinking.

\section{Inovação baseada em tecnologia versus inovação baseada em design}

Iniciamos esta discussão definindo as duas inovações, uma baseada em tecnologia e a outra em design, que é diferente do termo inovação tecnológica (em desuso). Inovação baseada em tecnologia traz avanço tecnológico, utiliza conhecimento tecnológico. Inovação baseada em design é relativa a significados, pois trata com conhecimentos de linguagens e significações.

Inovação baseada em design (VERGANTI, 2010) preocupa- se com a utilidade funcional de um produto, seu significado, ou ambos. Assim como a inovação funcional pode implicar uma melhoria tecnológica de performance incremental ou radical, também a inovação na dimensão semântica pode ser mais ou menos radical.

A inovação de significado é incremental quando adota a linguagem do design e entrega a mensagem no atual modelo de evolução socio- cultural. No entanto, inovação de significado pode ser radical quando o produto tem a linguagem e entrega da mensagem que implica a significante reinterpretação dos significados.

A inovação baseada em design reforçada pelo modelo GEiDa trabalha no modelo sociocultural atual, parte do levantamento de conhecimentos em informações pertencentes aos consumidores existentes no atual paradigma social.

A inovação baseada em design incremental começa com os insights dos usuários imersos no contexto sociocultural atual, este contexto rege as interpretações de significados. Por conta disso, torna-se mais rápida e tem um custo mais baixo, pois não necessita de mudanças no contexto social, pois ainda responde às necessidades do mercado vigente.

O exposto acima sugere que qualquer inovação implica na compreensão do mercado e das tecnologias vigentes, e que apesar das mudanças no paradigma tecnológico ter sido principalmente impulsionado pela tecnologia, a inovação incremental em uma tecnologia existente é basicamente Market Pull.

Nas dimensões da inovação Verganti (2010) mapeou três modos presentes na figura 4. A primeira é a Inovação baseada no design, que inicia com a compreensão das entrelinhas e das dinâmicas não faladas no modelo sociocultural e resulta na proposta radical de novos significados e linguagens que frequentemente implicam na mudança do regime sociocultural, no entanto pode não mudar, então este modo pode gerar inovação radical ou incremental. 


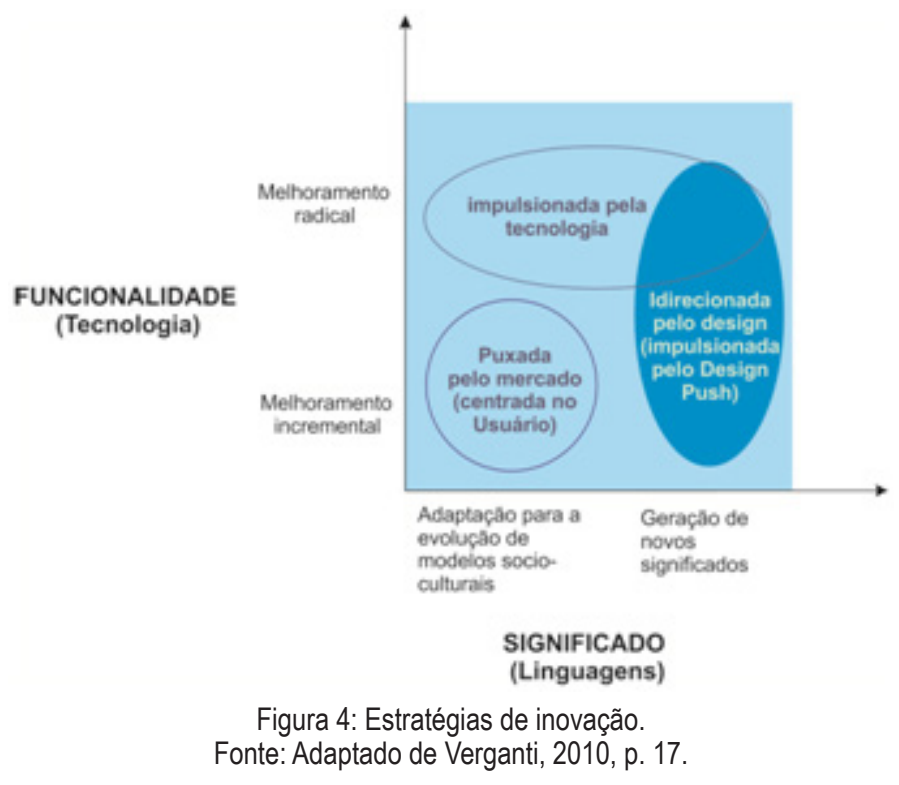

A segunda é a Inovação puxada pelo mercado, que inicia com a análise das necessidades dos usuários e busca por tecnologias e linguagens que os satisfaçam. A inovação centrada no usuário é alocada nesta estratégia, apesar de ser mais avançada e sofisticada em suas tecnologias, permitindo a melhor compreensão de porquê e como pessoas conferem significados às coisas.

Por último, a Inovação baseada em tecnologia, resultado da pesquisa tecnológica. A sobreposição entre a baseada em tecnologia e a baseada em design, no canto superior direito do diagrama, demonstra que avanços nas mudanças tecnológicas estão frequentemente associados às mudanças radicais de significado do produto, ou seja, mudanças no paradigma tecnológico são frequentemente alinhadas com mudanças dos regimes socioculturais.

Observamos que tanto a inovação baseada em tecnologia como a inovação baseada em design necessitam de um profundo entendimento das dinâmicas de mercado, análise de necessidades do usuário, e também exploração de novas tecnologias, portanto as habilidades do design thinker devem ser utilizadas para o entendimento destes contextos.

Para poder lidar com a inovação baseada no design é necessária uma capacidade de compreensão, antecipação e propósito que influenciam o surgir de novos significados. Os conhecimentos sobre as sutis e não expressas dinâmicas do modelo sociocultural são tácitos, não é codificado em livros ou em cenários sociológicos do futuro, e esse conhecimento é distribuído. A modelagem do modelo sociocultural e o impacto dele na interpretação da linguagem dos produtos depende de milhões de interações imprevisíveis entre os usuários, empresas, designers, produtos, centros culturais, mídia comunicacional, escolas, artistas, entre outros.

Os Design Thinkers valorizam a interação com esta rede de atores. Eles consideram estes atores como intérpretes da evolução do cenário futuro, com a qual devem compartilhar as suas próprias visões, trocar informações em tendências e testar a robustez de suas suposições.

É preciso não confundir a inovação baseada no usuário com a inovação baseada 
em design. A primeira centra somente em um ator, o usuário, e não tenta compreender como ele atribui significado às coisas. A segunda trabalha com rede de atores e foca nos seus relacionamentos para compreender como significam as coisas, para poder mudar os significados.

Denomina-se de Rede de Relacionamento de Discurso do design, (VERGANTI, 2010) "um processo coletivo de pesquisa em significados e linguagens, [...] um diálogo contínuo com modelos socioculturais (visualizado e desejado) e as implicações no padrão de consumo e linguagens de produto, ocorrido por meio de várias interações tácitas e explícitas entre vários atores em cenários locais e globais".

Este processo difere-se da abordagem baseada no usuário, tanto pela natureza como pelos atores (figura 4). As características básicas desta abordagem são:

- Um processo de pesquisa em rede (inovação aberta).

- Extrapola as fronteiras da empresa, incluindo usuários, mas também vários outros intérpretes.

- Baseada no compartilhamento de conheci-mento.

- Também inclui a ação de influência e modificação do regime sociocultural.

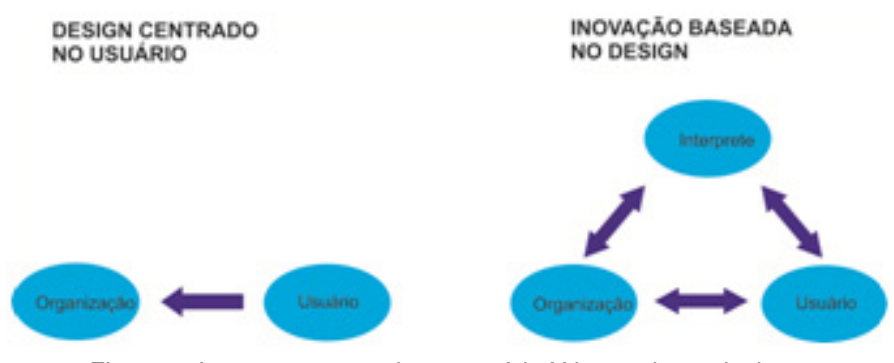

Figura 5: Inovação: centrada no usuário $X$ baseada no design. Fonte: Adaptado de Verganti, 2010, p. 22.

A capacidade chave no design centrado no usuário é aproximar-se do usuário, explicitar seus desejos e ser criativo para encontrar soluções. A capacidade chave da inovação baseada em design é acessar e compartilhar conhecimentos utilizando o discurso do design, e mais precisamente, identificar os intérpretes chaves, atraí-los e desenvolver com eles um privilegiado relacionamento, para compartilhar e recombinar conhecimentos e assim construir uma proposta única. Ela tem o mérito de ter feito os pesquisadores da gestão do design moverem-se do desenvolvimento de produto, para a geração de conceito.

Para o uso da inovação baseada no design nas empresas o difícil é acessar e internalizar conhecimentos do discurso de design, para o qual necessita do design thinker, um dos intérpretes do discurso de design, e de todas suas habilidades que auxiliam a organização a ter acesso a esse discurso (do design).

O design thinker possui diferentes habilidades que muitas vezes não estão presentes em uma só pessoa. Algumas vezes estas habilidades auxiliam na construção de ligações entre os diferentes mundos socioculturais e industrias, e que facilitam a transferência dos conhecimentos de significados e linguagens entre diferentes contextos. Na inovação baseada em design, essas pessoas são chamadas de guardiões de portas: os gatekeepers (VERGANTI, 2010). Elas facilitam o acesso dos clientes ao discurso de design sobre as linguagens do design, quando construídas trazem co- 
nhecimentos para o processo, ajudam os clientes a interpretar o discurso de design, e a se posicionar neste discurso.

O que é característico da inovação baseada no design é que designers agem como polinizadores de conhecimento em linguagens e em tecnologia.

Destaca-se que o acesso à informação externa não deve estar restrita somente aos gatekeepers, mas a toda a organização. Portanto a organização deve ter a capacidade de absorção, pois sua habilidade é de compreender e valorar conhecimento externo, dar sentido, e aprender, e assim adotar novas abordagens. A inovação aberta e as habilidades do design thinker, devem ser adotadas, pois podem auxiliar a organização a construir a capacidade de absorção.

Baseado no exposto, admitimos que o processo de design é um processo impregnado de conhecimentos, que para serem extraídos e compartilhados é necessário o uso das habilidades do design thinker.

\section{Design thinking no processo de gestão de design}

Gestão de design gerencia o design, ou mesmo, o gerenciamento do processo de design (BEST, 2006). Para alguns o trabalho do gestor de design fica restrito ao projeto, e isso realmente aconteceu, quando a Gestão de Design foi definida como profissão.

A expressão gestão de design surgiu no Reino Unido em meados dos anos $60 \mathrm{~s}$, (MOZOTA, 2003) referia-se ao gerenciamento das relações entre agência de design e seu cliente. Em 1966, Michael Farr observa o surgimento de uma nova profissão, a de gestor de design, cuja missão era garantir a suave execução do projeto e manter uma boa comunicação com a agência de design, que buscou suas referências na escola de negócio.

Peter Gorb (MOZOTA, 2003), em 1990, define gestão de design como "O efetivo desdobramento pelos gerentes de linha dos recursos de design disponíveis para a empresa a fim de ajudar a empresa em atingir seus objetivos".

Em 1990, com a mudança de século se aproximando e a migração para uma sociedade pós moderna, que exigia uma postura mais flexível, dinâmica, adaptiva, colaborativa e humanista, as coisas começaram a mudar. Com isso, as definições começam a mudar também, as organizações veem a gestão de design não mais como um processo sistemático, regrado e exato, mas mais sistêmico, no qual os elementos se relacionam e juntos resolvem problemas, mudam e se adaptam. Para Mozota (MOZOTA, 2003), a gestão de design passa a ser a implantação do design como um programa formal de atividades na empresa, pela comunicação da relevância do design para realização das metas organizacionais de longo termo e para coordenar recursos de design no nível de atividade empresarial, e assim, atingir objetivos organizacionais.

A gestão de design é que irá estabelecer a inserção adequada do design na empresa. Esta ferramenta gerencia os recursos humanos e materiais da organização integrando áreas (marketing, produção, engenharia e outros) à alta direção, desde a concepção de um projeto, seu lançamento no mercado, até seu impacto ambiental, 
sendo ainda eficiente para criar e implantar uma cultura empresarial que afete positivamente a imagem da empresa, estando, portanto, enraizada na estratégia da empresa.

O modelo aqui apresentado está no nível mais complexo para ser trabalhado pela gestão de design, a gestão estratégica de Design, na qual o gestor deve criar a relação entre o design, estratégia e cultura da organização. O objetivo é controlar a consistência do trabalho do design na organização e introduzir design no processo de formulação da estratégia.

A gestão estratégica de design (MOZOTA, 2003) é gerência da contribuição do design para a formulação da estratégia: para definir as responsabilidades e as lideranças atribuídas ao design e sua contribuição para a cultura organizacional, busca oportunidades para adotar inovações de design e demonstrações múltiplas de identidade por meio do design.

Existem dois modelos de posicionamento estratégico de design:

- O modelo natural: surge na organização que considera o design como principal competência desde o início da empresa. Design é parte do esquema empreendedor do fundador.

- O modelo de design adquirido, ou design aprendido pela experiência: demonstra a valorização progressiva do design na empresa.

O modelo aqui proposto auxilia organizações do modelo de design adquirido, pois a sua competência principal não é design, embora seja utilizado para que se tornem inovadoras.

Neste nível de gestão, os designers são menos familiares com o processo estratégico emergente; no entanto, este é provavelmente o aspecto mais interessante da gestão estratégica de design: ela insere opiniões e ideias de design no processo coletivo estratégico. O padrão social e progressivo da formulação da estratégia central é o mais útil para a inclusão do design na empresa.

A criação de uma estratégia articula duas lógicas: a lógica de análise (positivismo) e a lógica de design (construtivismo). Na segunda é que ocorre a contribuição do designer, que trabalha com a visualização do futuro, que por sua vez se dá no pensamento divergente do designer. A visão do futuro quebra a rotina e propõe caminhos radicalmente diferentes para contemplar a realidade futura e questionar as condições que são consideradas normais na empresa (MOZOTA, 2003).

A estratégia é dirigida para a interação. A empresa é orientada simultaneamente acerca do objeto e do sujeito. A habilidade de produzir beleza, inerente ao designer, pode ser vista como um sinal de poder utilizado pela relação estratégica. Segundo Mozota (MOZOTA, 2003), "estético é um tipo de doação que autentica a interação entre empresa e cliente". Nesse contexto, a gestão de design é fonte de vantagem competitiva ao auxiliar a relação estratégica em três direções complementares:

- Na criação de produtos e retórica

- Na criação da intenção estratégica e sua lógica de mudança;

- Na criação de uma ética do estético.

A abordagem cognitiva desenvolve a ideia pela qual a empresa tem acesso ao 
seu ambiente graças a uma seleção de representações, ou imagens mentais deste ambiente. Esta abordagem, explica a importância da identidade para o design estratégico:

A identidade da empresa repousa sobre um conjunto de representações. Estas são imagens associadas internamente e externamente à organização. As imagens são comunicações recebidas que equilibram a identidade presente (a realidade da organização), a identidade sonhada (a intenção estratégica), e a identidade aceitável (a interação com o meio ambiente)[14].

A identidade visual é definida diferentemente por conceitualizadores visuais (a escola do design) e conceitualizadores verbais (a escola de negócios). Por anos, a escola visual foi negligenciada, aumentando o domínio de autores da escola verbal. Hoje, gestores de design devem participar, na gerência, da identidade gráfica e arquitetônica e na construção de uma identidade coletiva, uma identidade organizacional, que foca a atividade, o estilo ou comportamento, ou o líder. Uma vez escolhida a estratégia de design, ela tem que ser disseminada na organização, pois, a "estratégia de design é um plano que auxilia difundir o design pela empresa" (MOZOTA, 2003).

Definir uma estratégia de design significa escolher um posicionamento estético que irá ser a expressão da abordagem do design da organização. Essa escolha determinará a posição que o design ocupa na estrutura organizacional.

Independente do seu nível, o processo de Gestão de Design é impregnado de momentos de tomada de decisão. O tomador de decisão é o gestor de design; portanto, deve utilizar, de maneira eficiente, os métodos e técnicas de extração e conversão do conhecimento. O modelo aqui demonstrado foi desenvolvido para médias e pequenas organizações, que são impregnadas de conhecimento tácito e culturais (não explicitáveis, mas sim compartilháveis na relação um para um).

A gestão de design trabalha essencialmente com conhecimentos. Na realidade, o próprio design é um conhecimento que extrai e converte o conhecimento organizacional e do consumidor em produtos e imagens (ou sistemas gráficos). Entendemos como conhecimento organizacional todo o conhecimento que a empresa dispõe, além dos conhecimentos óbvios como o objetivo e o explícito, incluímos o cultural (que envolve tradição) e o conhecimento tácito (aquele adquirido ao longo dos anos, por experiência).

Com base nesta premissa, pode-se afirmar que o processo de Gestão de Design é um processo de gestão do conhecimento e a organização, para ser inovadora, precisa, no seu processo de DNP, adotar primeiramente a busca por novo conhecimento, ou a exploração (exploration), a exploração no termo de aproveitamento. De acordo com James Mach seria

"maximizar o payoff a partir de um conhecimento existente" (refinando-o pelos estágios do conhecimento), ou seja, trabalhando uma heurística de sucesso. Ambos são importantes para a criação de valor e o sucesso da organização (MANUAL DE OSLO, 2015).

Para tanto, adota-se uma abordagem para inovação centrada no ser humano, muito utilizado por designers, que observam como as pessoas se comportam e como o contexto de suas experiências afetam as suas reações, em relação a produtos e 
serviços. Por envolver mais que um ator é considerado a inovação baseada em design, pois estes levam em conta o significado emocional das coisas, ao mesmo tempo em que o seu desempenho funcional. A abordagem centrada no ser humano é uma das características do design thinking; portanto, no intuito de evidenciar a natureza conceitual das organizações e utilizá-la como diferenciação, é necessário utilizar o design thinking enfatizando suas habilidades.

Segundo Veryzer e Mozota (2005), o design é o fator central de humanização inovadora de tecnologias e um fator crucial de mudança cultural e econômica. $O$ design thinking auxilia a integrar no processo de DNP o consumidor e os demais sujeitos, agindo como um agente integrador entre as diferentes disciplinas envolvidas no processo de DNP.

O design thinking é um processo criativo baseado na construção de ideias (ILIPINAR, 2008). Não havendo julgamento, ele elimina o medo de falhar e encoraja a máxima absorção e participação das pessoas no processo de resolução de problemas. Não é um conjunto de métodos, mas uma maneira de pensar que reforça o uso das habilidades adquiridas por designer com o passar dos anos e atitudes frente ao problema. Facilita a integração de grupos multidisciplinares e a colaboração durante o processo de DNP inovadores.

O processo de DNP atualmente tem sido composto por pessoas de diferentes backgrounds, cujas características funcionais, demográficas e psicológicas podem influenciar a performance deste grupo. Muitos estudos demonstram que a diversidade funcional tem um impacto no cumprimento de desafios e em relacionamentos do grupo. Já vimos que algumas áreas de membros deste grupo os levam a buscar inovação baseada em tecnologia e outros, como o designer, geram inovação baseada no ser humano.

Para o Martin (2009) é o design thinking que promove o equilíbrio entre o pensamento analítico e o intuitivo, permitindo às organizações gerar inovações para aumentar a eficiência e competitividade. Rique Nitzsche (MARTIN, 2009) fala em uma abordagem que utiliza a sensibilidade e os métodos de um designer para resolver problemas e atender as necessidades de pessoas, de forma que seja tecnologicamente e comercialmente viável. Em outras palavras, design thinking é inovação centrada no ser humano.

\section{Habilidades do design thinker e o dna de inovadores}

O modelo conceitual demonstrado neste artigo pretende auxiliar o processo de inovação nas organizações pelo uso de algumas habilidades dos design thinkers.

Dyer, Gregersen e Christensen (DYER, GREGERSEN, e CHRISTENSEN, 2011) concordam que a inovação é desencadeada pela habilidade que esses inovadores possuem de unir ideias (chamam essa habilidade cognitiva de pensamento associativo), no entanto, inovadores pensam não só de maneira diferente, como também agem de forma diferente. Alguns observam o mundo com uma intensidade maior que as pessoas comuns. Outros criam networks com outras pessoas criando um grupo colaborativo, enquanto outros se engajam em ações experimentais. A inovação e a criatividade não é só uma habilidade cognitiva, mas também uma questão de comportamento. 
A criatividade é a engrenagem para a inovação e tem que ser praticada. É uma habilidade natural humana, mas que perdemos a medida que crescemos, talvez pela timidez ou medo da crítica. Ela pressupõe a combinação de ideia + coragem.

Os autores criaram um modelo que demonstra o DNA de inovadores para gerar ideias inovadoras, demonstrado na figura 5, abaixo.

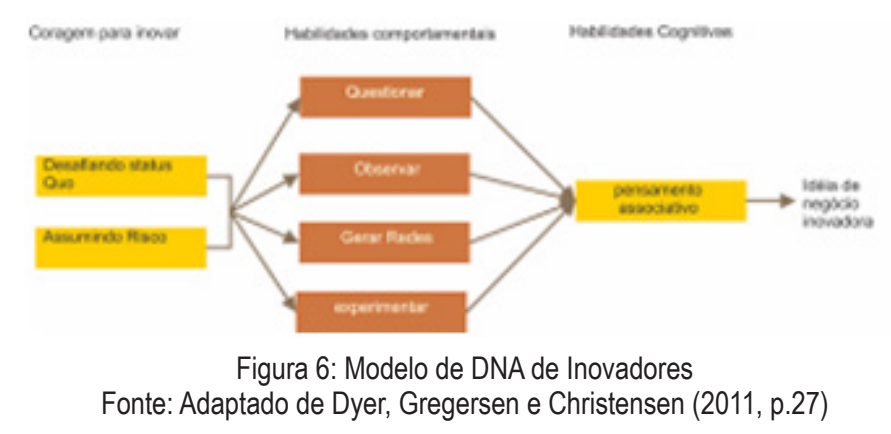

As habilidades comportamentais, e cognitivas dos inovadores são as mesmas do design thinkers. Para Brown [2] o design thinking inicia com as habilidades que os designers aprenderam no decorrer do tempo, como: a de alinhar as necessidades dos seres humanos com os recursos tecnológicos disponíveis na organização; na intuição; na habilidade de reconhecer padrões; construir ideias que tenham significado tanto emocional quanto funcional; na habilidade de questionar o entorno e ser empático; e na habilidade de expressar-se de outra maneira que não em palavras ou símbolos. Essa última uma das mais importantes habilidades do designer, porque "O ato de desenhar parece clarear meus pensamentos." (MOZOTA, 2003), pois o processo do design, ao que parece, é difícil de conduzir por processos mentais puramente internos; o designer precisa interagir com uma representação externa.

Acontece que há um limite cognitivo para a quantidade de complexidade que pode ser manuseada internamente; esboçar fornece um depósito temporário e externo para ideias tentadas, e essa externalização suporta o diálogo que o designer tem entre o problema e a solução.

O designer utiliza o processo de desenho tanto como um processo de crítica como de descoberta. Ele utiliza o desenho como meio de materialização, imaginação, ou descoberta de algo que não pode ser construído na sua mente, e também como um meio de comunicação com os outros. De acordo com Cross [20] nesses casos, o design torna-se não só um processo pessoal e cognitivo, como um processo partilhado e social. Esse processo leva a outra habilidade que, segundo Brown (2009), é a de trabalhar de forma interdisciplinar e de criar redes.

Os códigos visuais desenvolvidos pelo designer, quando explicitam os conhecimentos externalizados, facilitam a colaboração em projetos. O design thinker observa o ordinário e grava as suas observações e ideias visualmente; ele tem em si a habilidade de expressar suas ideias visualmente. A cultura do design thinking encoraja o protótipo, que não deixa de ser uma maneira de pensar visualmente. Para um design thinker, o protótipo não é só uma maneira de validar ideias finais, mas é também um processo de criação. A única premissa é que os protótipos precisam ser testáveis, mas não necessariamente físicos. De acordo com Brown (2009), protótipos podem ser 
storyboards, cenários, filmes, e até um improviso teatral.

Praticantes competentes do design thinking geralmente sabem mais do que conseguem dizer. Eles exibem um tipo de saber-na-prática, em sua maioria é conhecimento tácito. Ele identificou um processo cognitivo de reflexão-em-ação como a inteligência que guia o comportamento 'intuitivo' em contextos práticos de pensar-e -agir, algo como 'pensando sobre seus pés' (thinking on your feet). Refletir-em-ação é um quadro experimental no qual o design thinker encontra uma maneira de ver a problemática nas mãos, ou seja, em forma de protótipos.

Pode-se observar a semelhança entre as habilidades e atributos do design thinker com o DNA de inovadores. O quadro 1 abaixo mostra essa relação (DEMARCHI, FORNASIER, ORTUÑO, e MARQUINA, 2014).

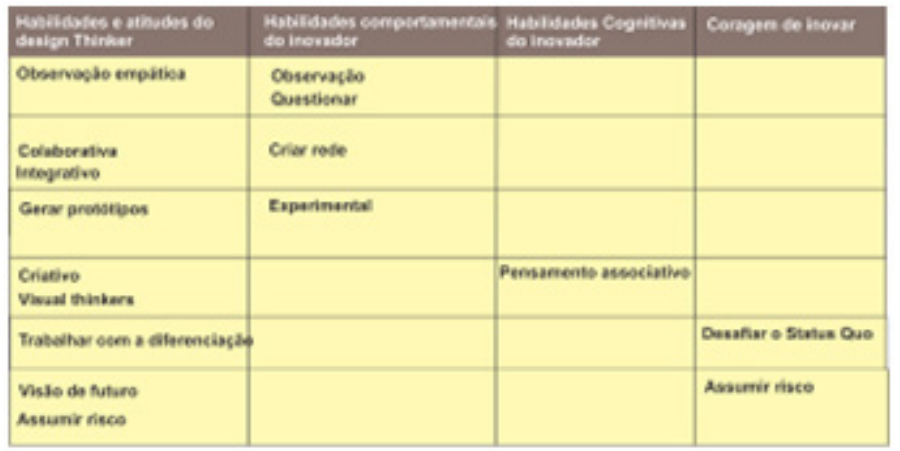

Quadro 1: comparação entre as habilidades e atitudes do design thinker com o DNA do inovador Fonte: Demarchi, Fornasier, Ortuño e Marquina, 2014, p. 3231.

O design thinking auxilia na inserção da inovação baseada em design utilizando todo o potencial do designer de identificar padrões e gerar ressignificações, por meio de códigos visuais, a partir da maior habilidade do designer: o visual thinking.

\section{O modelo geida}

O processo de Gestão Estratégica Design está representado horizontalmente na Figura 6. O modelo GEiDa (DEMARCHI, FORNASIER, MARTINS, 2013) é dividido em Design Estratégico, Operacional e Estratégico/tático, que abrange a Conversão/ Produção do Conhecimento e a Integração do Conhecimento. O modelo possui sete espaços (o oitavo ainda está em fase se estudo, ainda não delineado) e a eles se sobrepõem quatro ciclos de divergência e convergência.

A Oportunidade: desencadeada pela empresa, quando sente a necessidade de mudar e busca no design a oportunidade de inovar. É definido um briefing com informações básicas conseguidas com o repositório estratégico, ocorrendo uma redução do conhecimento. 


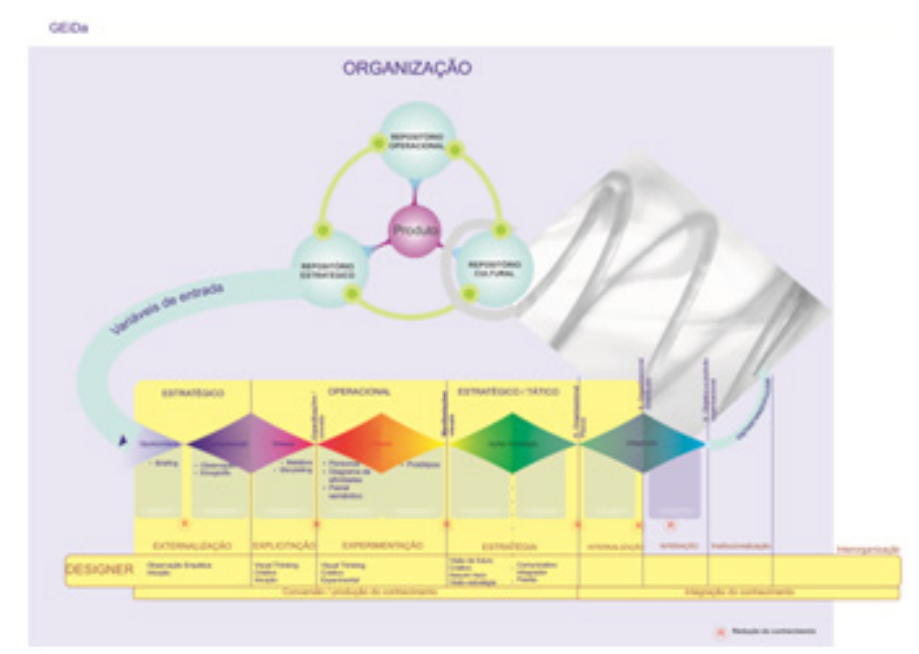

Figure 7: Modelo GEID aprimorado (GEiDa)

A observação: Nesse espaço, o designer observa empaticamente as relações, vivencia o processo de desenvolvimento de produto. Observa o uso do produto e ouve as histórias dos membros da organização sobre a sua formação, com intuito de se colocar empaticamente no lugar dos membros, para que possa realmente compreender o seu conceito. Aqui utiliza diversas técnicas para auxiliar a externalização e enfatizar as habilidades de observação empática e intuição do design thinker. O pensamento divergente, que ocorre neste espaço, pode ser o caminho para a inovação, que primeiro, amplia o conhecimento sobre o universo a ser trabalhado, analisa os conhecimentos e informações levantados, para depois sintetizar normalmente orientado por técnicas como metáfora e/ou analogia.

A Compreensão objetiva definir o escopo do projeto e suas fronteiras, além de identificar os perfis dos usuários e outros atores-chave que deverão ser abordados, quando será possível verificar que áreas de interesse devem ser exploradas e que forneçam insumos para a elaboração dos temas que serão investigados, quando ocorre a imersão profunda do designer na organização.

Uma vez impregnado desse conceito, por meio do pensamento convergente, o designer inicia o espaço de Síntese pela contação de histórias e o pensamento visual, assim extrai padrões significativos de uma massa de informações cruas (BEST, 2006), fundamentalmente é um ato criativo, originando outra redução do conhecimento. Mais uma vez é necessário o uso de diversas técnicas de externalização do conhecimento, aplicadas por meio das habilidades de visual thinking, criativas e mais uma vez a intuitivas.

O processo de design operacional inicia no espaço da Criação, quando o designer utiliza todo seu conhecimento explícito com o conhecimento tácito e as habilidades criativas e experimentais, e converte o conceito em conhecimento objetivo. Aqui, inicia-se outro ciclo de divergência e convergência, que o designer amplia pelas técnicas criativas para depois sintetizar e reduzir, utilizando a habilidade experimental e colaborativa a partir de diversos tipos de protótipos. O ciclo das Ações Estratégicas acontece quando o designer, pelas habilidades de visão de futuro, criativas e postura de assumir risco, desenvolve as propostas estratégicas de aplicações das manifestações visuais, num documento intitulado planificação visual de gestão de 
design (plano estratégico) num ciclo de divergência e convergência e encerra a Produção do Conhecimento pela quarta redução do conhecimento.

Inicia-se, então, a segunda fase da Gestão de Design: a Integração do Conhecimento, que é o processo de aprendizagem da organização, quando ela absorve as estratégias formuladas para colocá-las em prática, e assim ocorre o último ciclo de divergência e convergência. A fase de Gestão Estratégica é estimulada pelo agente de aprendizagem que utiliza mecanismos de aprendizagem para que aconteçam as mudanças dos mapas cognitivos dos colaboradores quanto às novas estratégias (pensamento divergente), que irão ser adotadas pela organização, configurando-se o processo de aprendizagem individual, quando ocorre a internalização. Após a adoção do novo conhecimento, inicia-se a Interação pelo processo colaborativo, a partir do compartilhamento dos mapas cognitivos construindo um novo mapa cognitivo situado (pensamento convergente), quando termina o processo de Gestão de Design e ocorre outro processo de redução como os outros, que se for excessiva deforma o conhecimento.

A Institucionalização do Conhecimento Organizacional Distribuído (COD) ocorre pelos mapas cognitivos situados que são transformados em ações rotinizadas. Este espaço é realizado pela organização de forma colaborativa.

Por último, ocorre a Intraorganização, pelo compartilhar do COD explicitado, através de uma Gestão de Redes Colaborativas externas.

\section{Aplicação do modelo}

O modelo foi aplicado em várias organizações, pelo LabCONDE (Laboratório de Conhecimento em Design Estratégico e Conexões), um grupo de pesquisa da Universidade Estadual de Londrina, PR, por meio de uma pesquisa de natureza exploratória, utilizando como delineamento o ex-post-facto, podemos compreender a importância do modelo para auxiliar na inserção da inovação incremental baseada em design. Aqui mostramos de que forma o modelo foi aplicado, pelo atendimento do Laboratório às organizações.

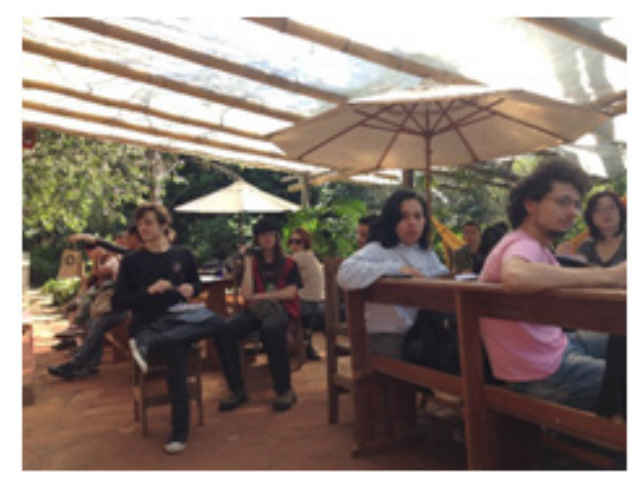

Figura 8: Visita à organização

O modelo leva o designer a extrapolar a organização fazendo com que fique próximo do consumidor/usuário, mas também identifique os demais atores no processo da organização. Faz com que o designer acesse e compartilhe conhecimentos utilizando no discurso de design, e mais precisamente, identifica os intérpretes 
chaves, para atraí-los e desenvolver com eles um relacionamento privilegiado, para compartilhar e recombinar conhecimento, no intuito de construir uma proposta única. (figura 7).



Figura 9: Códigos visuais externalizados

Após a etapa de compreensão, os designers retornam ao escritório e em grupo externalizam os conhecimentos adquiridos, algumas vezes juntamente com os empresários. Assim, inicia-se obrigatoriamente, o espaço de síntese, que gera os conhecimentos explicitados em forma de códigos visuais. Aqui, sentimos a necessidade de obter novas técnicas para externalizar e compartilhar os conhecimentos (figura 8).

A partir dos conceitos externalizados, iniciamos o espaço de criação e manifestações visuais, foram gerados desenhos de ideias e depois protótipos, chegando ao produto proposto.

O espaço de ações estratégicas é caracterizado pela criação de uma planificação visual que contém todas as propostas de produtos e de ações que envolvem o design e de que forma podem ser adotas para a sua inserção na empresa em curto, médio e longo prazo (figura 9).
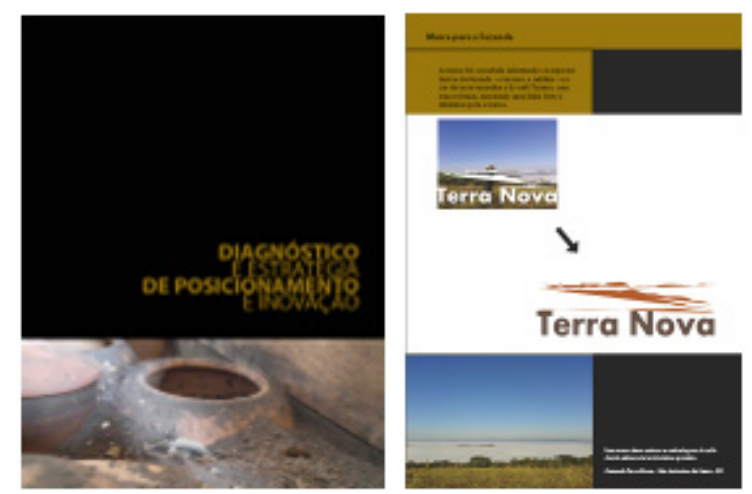

Figura 10: Exemplo de planificação visual das ações estratégicas. Designer: Marcelo Kalau (LabCONDE)

A segunda parte, da integração do conhecimento do modelo, ainda não foi aplicada. 


\section{Conclusão}

Após a aplicação do modelo fica evidente que o GEIDa é um modelo conceitual que permite a aplicação do Design Thinking, bem como atingir tanto a inovação incremental baseada em design, quanto a inovação radical, dependendo das necessidades.

No entanto, podemos perceber também que é necessário que em cada espaço crie-se planilhas, de preferência visual, que auxiliem nas externalizações, criações e gerações de ações estratégicas para que o modelo seja realmente realizado com todos os seus espaços.

Também está sendo criado um software para armazenamento dos dados e informações geradas no processo, para ser aplicado em processos futuros, assim como para a visualização de cada espaço que o grupo estará trabalhando, e desta forma não perder o foco do projeto.

Considerando que, ao estabelecer qualidades de objetos, processos, serviços e seus sistemas, o design é o fator central da humanização inovativa das tecnologias e é o fator crucial da troca cultural e econômica. Considerando aqui a tecnologia como conhecimento, então, a inovação do conhecimento é responsável pelas trocas culturais: depende da cultura e gera cultura, como um ciclo. Cultura é um padrão transmitido historicamente, de significados incorporados em símbolos, um sistema de concepções herdadas, expressas em formas simbólicas, por meio das quais os homens se comunicam, perpetuam e desenvolvem seu conhecimento e suas atitudes acerca da vida (GEERTZ, 1989).

Implantada por designers e entusiastas, o momento no Brasil é de vantagem para a inovação, a começar pela cultura brasileira e sua criatividade natural. As pequenas empresas levam ainda mais vantagem: não sofrem com tanta burocracia e gerenciamento intermediário (que atrapalha o caminho da inovação), conseguindo ser mais rápida, mais ágil ou mais flexível que as grandes e contam agora com leis de incentivo à inovação nas esferas municipais, estaduais e federais, que podem ser uma entrada importante para o design e sua gestão.

\section{Referências}

BEST, K., "Design Management: Managing Design Strategy, Process and Implementation", "eds.", AVA, Switzerland, 2006.

BROWN, Tim, "Change by design: how design thinking transforms organizations and inspires innovation,"eds." HarperCollins, New York, 2009,

CHESBROUGH, H. "Inovação Aberta: como criar e lucrar com a tecnologia", "eds." Bookman, Porto Alegre, 2012.

CROSS, N. "Designerly Ways of Knowing", "eds.", Birkhauser verlag AG, Boston, 2007. DAUSCHA, R. "O que é estatal de Inovação Aberta", disponível em, https://endeavor. 
org.br., 2012.

DAVILA, T., EPSTEIN, M. J., SHELTON, R., "As regras da inovação: como gerenciar, como medir e como lucrar", "eds.", Bookman, Porto Alegre, 2007.

DEMARCHI, A.P.P., FORNASIER, C.B.R., MARTINS, R.F.F. "Strategic Integrator Design Management Model Enhanced", Proceedings of International Conference on Integration of Design, Engeneering and Management for Innovation- IDEMI. "eds.", IDMEC, volume1, "pp." 201-209, 2013.

DEMARCHI, A.P.P., FORNASIER,C.B.R., ORTUÑO, B.H., MARQUINA, E.S.R."id-think: facilitador da visualização dos conhecimentos da empresa", Anais do 11 Congresso Brasileiro de Pesquisa e Desenvolvimento em Design, "eds." Edgard Blucher, v.1. "pp." 3226-3237, 2014.

DYER, J., GREGERSEN, H., CHRISTENSEN, C. "The innovator's DNA: Mastering the five skills of disruptive innovators", "eds.", Havard Bussiness Review Press, Havard, 2011.

GEERTZ, Clifford. "A interpretação das culturas", Rio de Janeiro: Ed. Guanabara, 1989.

ILIPINAR, G. "Design Thinking in postmodern organization." Anais International DMI Education Conference, France, 2008.

LEI DE INOVAÇAO disponível em http://www.planalto.gov.br/ccivil_03/_Ato20042006/2004/Lei/L10.973.htm, acesso maio 2015.

MANUAL DE OSLO. "Finep", disponível em, www.finep.gov.br/dcom/brasil_inovador/capa.html, acesso em, fev.2015.

MARTIN, R. "The design of business: Why design thinking is the next competitive advantage", "eds.", Harvard Bussiness Press, Boston, 2009.

MORACE, F., "org". "Consumo Autoral: As gerações como empresas criativas", "eds.", Estação das Letras e Cores, São Paulo, p.135, 2009.

MOZOTA, B. B. “Design Management: Using to build brand value and corporate innovation", "eds." Allworth Press, New York, 2003.

ROMANINI, V. "Design como comunicação: uma abordagem semiótica”, Design: Quo Vadis? Anais do I Seminário do Cursos de Design da FAUUSP, "eds." FAUUSP, São Paulo, volume I, "pp." 75-80, 2008.

TERRA, J. C. C. , "org.". "Inovação: quebrando paradigmas para vencer", "eds." Saraiva, São Paulo, 2007. 
VERGANTI, R. "Design, meaning and radical innovation: meta-model and research agenda", Jornal of Product Innovation Management, volume 27, "pp." 1167-1180, 2010.

VERYZER, R. W., MOZOTA, B. B. de . "The impacto $f$ User-Oriented Design on New Product Development: Na Examination of fundamental Relationships", Jornal of Product Innovation Management, Volume 22, "pp." 128-143, 2005.

XAVIER, C. M. S. "Gerenciamento de projetos de inovação, pesquisa e desenvolvimento de produtos", "eds.", Brasport, Rio de Janeiro, 2014. 